\title{
ARTTIRILMIŞ GERÇEKLİK İLE SCRUM TASK BOARD UYGULAMASI
} ***

\author{
SCRUM TASK BOARD APPLICATION WITH AUGMENTED REALITY
}

Emin BORANDAĞ $\breve{G}^{*}$ Fatih YÜCALAR**

\begin{abstract}
$\ddot{O} \mathbf{z}$
Yazılım geliştirme teknolojilerinde yaşanan gelişmeler, yazılımların geliştirilmesinde kullanılan yazılım yaşam döngülerinin sürelerinin kısalması, yazılımlardaki kapsamin ve gereksinimlerin artması ile beraber farklı çevik yazılım geliş̧irme yaklaşımlarını ortaya çıkarmıştır. Çalışmada bir çevik yazılım geliş̧tirme yöntemi olan SCRUM detaylı olarak anlatılmış ve farkl teknolojilere göre gelişstirilen web ve arttırılmış gerçeklik temelli iki SCRUM Görev Tahtası uygulamasının kullanımı ile elde edilen sonuçlara yer verilmiştir. Gelişstirilen arttırılmış gerçeklik temelli Scrum Görev Tahtası uygulaması, web-tabanlı Scrum uygulamasının gerçekleştirdiği işlemleri yapabilmektedir. Geliştirilen her iki uygulama karşılaştırıldığında, web-tabanlı Scrum Görev Tahtası uygulamasının AR tabanlı Scrum Görev Tahtası uygulamasina göre kullanımının daha kolay olduğu, daha az teknoloji ve teknik bilgi gerektirdiği görülmüşür.
\end{abstract}

Anahtar Kelimeler: Scrum, Yazılım proje yönetimi, Yazılım kalitesi, Arttırılmış gerçeklik.

\begin{abstract}
Developments in software development technologies, software life cycle used in the development of software cycles, shortening of the scope of the software and with the increase in the requirements of different agile software development approaches have emerged. In this study, SCRUM method, which is an agile software development method, is explained in detail and the results obtained with the use of web and augmented reality based two SCRUM task board application according to different technologies are given. The augmented reality based Scrum Task Board application can do the same operations as the web-based application. When both applications were compared, it was seen that web-based Scrum Task Board application was easier to use than augmented reality based Scrum Task Board application and required less technology and technical knowledge.
\end{abstract}

Keywords: Scrum, Software project management, Software quality, Augmented reality.

\footnotetext{
* Dr. Öğr. Üyesi, Yazılım Mühendisliği Bölümü, Teknoloji Fakültesi, Manisa Celal Bayar Üniversitesi, Manisa,

Türkiye, ORCID: 0000-0001-5553-2707

** Dr. Öğr. Üyesi, Yazılım Mühendisliği Bölümü, Teknoloji Fakültesi, Manisa Celal Bayar Üniversitesi, Manisa, Türkiye, ORCID: 0000-0002-1006-2227
} 


\section{GíRiș}

Yazılım geliştirme süreci diğer ürün geliștirme süreçlerinden farklı olarak uzun zaman alan, karmaşık ve sıkıntılı bir dönemdir. Yazılım projeleri kötü proje yönetimi yüzünden kısmen başarılı olmaktadır. Günümüzde bir yazılım projesi, altı aylık süreç içerisinde tamamlanmazsa ve geliştirme sürecine müşteri dâhil edilmezse, bu projenin başarıya ulaşma ihtimali zayıftır (Yücalar ve Borandağ, 2019). Yazılım projelerinin geliştirilmesi süresince, yazılım sürümlerinin zamanında ortaya çıkarılamaması, müşterilerin talep etmiş olduğu değişiklik isteklerine hızlı bir şekilde cevap verilememesi, yazılım içerisinde ortaya çıkan hataların geç fark edilmesi ve projenin geliştirilmesi süresince sistemin kendi yapısını geliştirememesi gibi çeşitli problemler ile karşı karşıya kalınmaktadır. Belirtilen bu problemlere çözüm bulmak amacıyla, 90'lı yılların sonlarına doğru "çevik (agile)" olarak adlandırılan birbirine benzer çeşitli yazılım metotları geliştirilmiştir. Geliştirilen bu çevik yazılım geliştirme metotları, yazılım ürünlerinin hızlı bir şekilde piyasaya çıkarılmasını, değişen müşteri taleplerine hızla yanıt verilmesini ve kısa zamanda geliştirilen yazılım uygulamasını müşteri hizmetine sunmayı amaçlamaktadırlar (Çamoğlu vd., 2010). Genel hatlarıyla çevik yazılım geliştirme metotları, yüksek verimliliğe ve esnek bir mimariye sahip, daha az hatalı, hızlı ve ucuz çözümler sağlamaktadırlar. Kendi içerisinde özü aynı ancak uygulama aşamasında pratikleri farklılaşan çevik yazılım geliştirme metotlarına; XP (eXtreme Programming) (Schach, 2011; Beck ve Andres, 2004), SCRUM (Schwaber, 2004), RUP (Rational Unified Process) (Kruchten, 2003), TDD (Test-Driven Development) (Paranj, 2017), FDD (Feature-Driven Development) (Palmer ve Felsing, 2002), LSD (Lean Software Development) (Poppendieck ve Poppendieck, 2003), DSDM (Dynamic System Development Methodology) (Agile Business Consortium, 2019) ve MSF (Microsoft Solution Framework) (Turner, 2006) örnek olarak verilebilir.

Yazılım geliştirme sürecinin takibi çevik metodolojiler açısından oldukça önemlidir. Çevik yazılım geliştirme projelerinin yönetiminde kullanılmak üzere web-tabanlı birçok yazılım aracı geliştirilmiştir. Bu yazılım araçlarına örnek olarak; Jira (Atlassian, 2019; Arslan ve Yücalar, 2016), Trello (Writtenhouse, 2016), Taiga (Taiga Agile, 2019), Sendtask (Sendtask, 2019), Asana (Dijital Maden, 2019), Basecamp (Basecamp, 2019), Pivotal Tracker (Pivotal Tracker, 2019), Vivify Scrum (Vivify Scrum, 2019), Blossom (Blossom, 2019), Sprintly (Sprintly, 2019), Codebase (Codebase, 2019) gibi araçlar verilebilir. Yazılım ekiplerinin koordineli çalışabilmelerini ve aralarında etkili bir iletişim kurabilmelerini sağlayan bu proje yönetim araçları yazılım projelerinin takibini kolaylaştırmaktadır. Bunun yanında iş gücü ve zaman kaybını minimize ederek organizasyon içerisindeki verimin arttırılmasına da katkı sağlamaktadırlar.

Çalışmanın ikinci bölümünde çevik yazılım geliştirme yaklaşımlarından biri olan SCRUM metodolojisi ve temel kavramları ile SCRUM Görev Tahtasının (Task Board) çalışma mantığına değinilecektir. Üçüncü bölümde ise Endüstri 4.0 ile beraber hayatımıza giren önemli teknolojilerden biri olan sanal gerçeklik teknolojilerinden bahsedilecektir. Çalışmanın dördüncü bölümünde webtabanlı olarak geliştirilen "SCRUM Test Board" uygulaması anlatılacaktır. Beşinci bölümde Arttırılmış Gerçeklik (Augmented Reality - AR) teknolojisi kullanılarak geliştirilmiş "AR SCRUM Task Board" uygulamasından bahsedilecektir. Son bölümünde ise çalışma sonucunda elde edilen bilgilere ve gelecek çalışmalara yer verilecektir.

\section{SCRUM}

Jeff Sutjerland ve Ken Schawaber tarafından 90'lı yılların ortalarında geliştirilen Scrum, yazılım endüstrisinde en çok bilinen ve kullanılan çevik yazılım geliştirme metodolojilerinden biridir (Yücalar ve Borandağ, 2019). Aynı zamanda bir proje yönetim yaklaşımı da olan Scrum'da temel amaç bir takım halinde projenin oluşturulmasıdır. Temel kurallara ve esnek bir yapıya sahip olan Scrum metodolojisi, karmaşık bir yapıya sahip yazılım projelerini küçük birimlere (sprint) ayırarak geliştirmeyi öngörür. Bu metodolojinin kullanımı sayesinde değişime açık, müşteri gereksinimlerinin 
farklılaştığı küçük yazılım projelerinin geliştirilmesi mümkündür (Schwaber, 2004; Lacey, 2012). Scrum, gereksinimlerin kolaylıkla tanımlanamadığı, zaman içerisinde sürekli olarak farklılaştığı ve karmaşık durumların beklendiği yazılım projelerinde kullanılan bir yöntemdir.

Scrum'da geliştirilecek olan projenin alt adımları; bekleyen (backlog), devam eden (in progress), test edilen (testing) ve tamamlanan (done) olmak üzere dört başlık altında tanımlanır. Bu başlıklar altına yapılan tanımlamalar oldukça detaydan uzak ve temel düzeydedir. Scrum'da sprint (koşu) adı verilen aktiviteler bulunmaktadır. Sprint içerisinde süre ve görev tanımlamaları yapılmaktadır. Her bir sprint' in tamamlanmas 12-4 haftadan fazla sürmemekte ve ayaküstü günlük 15 dakikalık toplantılarla sürekli olarak iş planlarının takibi yapılmaktadır (Yücalar ve Borandağ, 2019; Schwaber, 2004). Toplantıya katılanlar projenin ilerleyişi hakkında genel bir bilgiye sahip olurlar. Bu sayede yazılımın yinelemeli ve artırımsal olarak geliştirilmesi sağlanmış olunmaktadır.

\subsection{Scrum'daki Temel Kavramlar}

Scrum'da roller, toplantılar ve araçlar olmak üzere üç temel kavram vardır. Bu kavramların detaylarına aşağıda yer verilmiştir.

\subsubsection{Roller}

Scrum'da proje ekibi üç farklı unvanda çalışan kişilerden oluşmaktadır. Proje ekibinde yer alan kişilerin görev ve sorumlulukları aşağıda ifade edilmiştir (Rubin, 2012; Deemer vd., 2012).

- Ürün Sahibi (Product Owner): Müşteri tarafından görevlendirilmiş, geliştirme takımı ile müşteri arasındaki iletişimden sorumlu kişidir. Projenin ilerleyişini kontrol eder ve geri dönüşler verir. XP'nin 12 pratiğinden biri olan ekipte müşteri pratiğinin Scrum'daki karş1lığ1 gibidir. Aynı zamanda bu kişi ekibin bir üyesidir.

- Scrum Yöneticisi (Scrum Master): Scrum metodolojisinin getirmiş olduğu temel kurallara, yöntemlere ve araçlara göre takımın çalışmasından sorumlu kişidir. Scrum ile yönetilen projelerde kilit rol oynayan Scrum yöneticisi, takımın geliştirilen proje ile uyumlu çalışmasını sağlamakla da görevlidir.

- Scrum Takımı (Scrum Team): Scrum yönetici tarafından proje gelişimi ile ilgili olarak belirlenen zaman hedeflerine göre süre tahminlerini yapan, sürekli iletişim halinde olan ve bir hedefi başarmak üzere mücadele eden yazılımcıların oluşturduğu takımdır. Genellikle bu takım 5 - 9 kişiden oluşur. Takım üyeleri, kendi kendilerini organize ederler.

\subsubsection{Toplantılar}

Scrum'da proje ekibinin gerçekleştirdiği üç farklı toplantı vardır. Her bir toplantıya ilişkin bilgiler aşağıda ifade edilmiştir (Sutherland, 2014; Asproni, 2006).

- Koşu Planlama (Sprint Planning): Scrum'da gerçekleştirilen en büyük ve kapsamlı toplantıdır. $\mathrm{Bu}$ toplantı içerisinde geniş kapsamlı gereksinim listesinin çıkarılması, görev dağılımının çıkartımı, risk planlaması ve zaman hedeflerinin tanımlanması gibi proje başarısını temel etkileyecek konular ele alınır.

- Koşu Gözden Geçirme (Sprint Review): Her bir koşu (sprint) başında gerçekleştirilen toplantıdır. Bu toplantı iki kısımdan oluşur. İlk kısımda ürün gereksinim listesini (product backlog) gözden geçirilir. Yapılan bu gözden geçirme sonucunda gereksinim hedefleri ve bu hedeflere ilişkin kapsam belirlenir. İkinci kısımda ise, takım koşu gereksinim listesini (sprint 
backlog) oluşturur. Takım üyeleri, önceliklendirilen gereksinimleri dikkate alarak gerekli taahhütleri yapar (Çamoğlu vd., 2010; Asproni, 2006).

- Günlük Scrum Toplantıları (Daily Scrum Meetings): Her iş günü içerisinde genelde sabahları olmak üzere belirlenen saatlerde tüm takımın katılımı ile gerçekleştirilen ortalama 15 dakikalık kısa süreli toplantılardır. Bir gün öncesinde hangi çalışmaların yapıldığı, bugün hangi kısımların yapılacağı ve eğer varsa problemler bu toplantı içerisinde konuşulur.

\subsubsection{Bileşenler}

Scrum'da ürün gereksinim dokümanı, koşu gereksinim listesi ve kalan zaman grafiği olmak üzere üç temel bileşen yer almaktadır. Bu temel bileşenlere ilişkin bilgiler aşağıda ifade edilmiştir (Sutherland, 2014; Asproni, 2006).

- Ürün Gereksinim Dokümanı (Product Backlog): Proje ile ilgili yapılacak işlerin yer aldığı, müşteri bakış açısı ile oluşturulmuş, detaydan uzak olarak hazırlanmış gereksinim listedir. Kullanıcı bakış açısından ele alınan bu doküman, genellikle kullanıcı hikâyelerinden (user stories) oluşur.

- Koşu Dokümanı (Sprint Backlog): Mevcut koşu için ürün gereksinim dokümanından elde edilmiş iş ve görevleri kapsar. Yazılım projesinin koşu sonunda elde edeceği kabiliyetlerin neler olacağına ilişkin bilgilerin bulunduğu bir dokümandır.

- Kalan Zaman Grafiği (Burndown Chart): Bu grafik, koşu (sprint) süresince hangi işlerin ne kadarının yapıldığı ile kalan işlerin ne kadarlık bir zamanda yapılacağını göstermektedir. Ayrıca bu grafik, geriye dönük çalışma çizelgesi döküm bilgisini de içermektedir.

\subsection{Scrum Task Board}

Scrum Task Board'un (Görev Tahtasının) çalışma mantı̆̆ı Şekil 1'de görüldüğü üzere hikâye (story) kartlarına dayanır. Müşteri görüşmelerinden elde edilen gereksinimler ve hikâye kartlarına göre görev paylaşımı ve takibi yapılır. Hikâye kartları önem derecesine göre en önemliden en az önemliye doğru sıralanır. Her bir hikâye kartı, "task" adı verilen ve teknik olarak tanımlanan görevlere ayrılır. Bu görevler dört bölümde toplanır. Bunlar "backlog” ya da diğer adı ile "to-do", "in progress", "testing" ve "done" kısmıdır. Bu sayede projenin ilerleyişi bir tablo üzerinden takip edilebilir. Tablonun kullanımı proje ekibinde bulunan herkese açıktır. Günlük gerçekleştirilen toplantılar bu tahta (board) üzerinden yapılır (Sutherland, 2014).

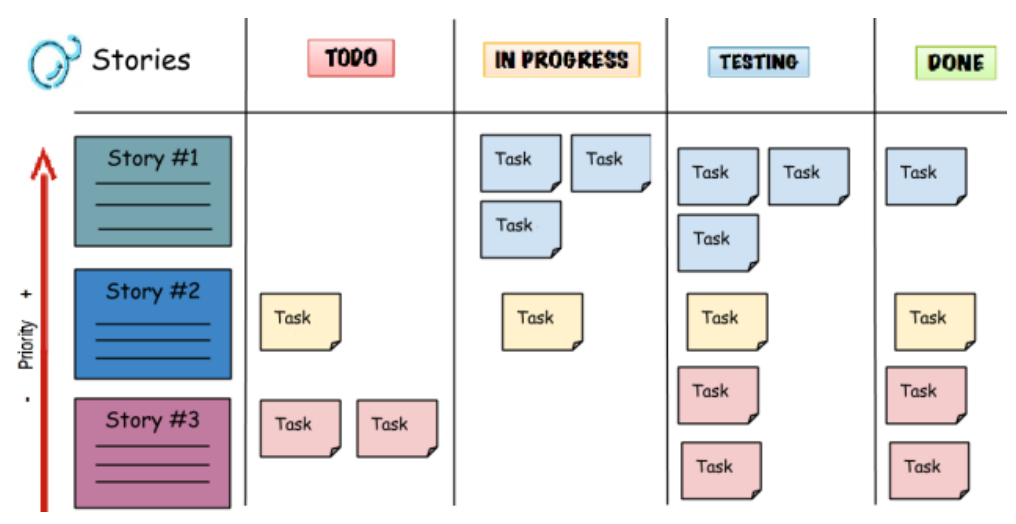

Şekil 1: Scrum Task Board Arayüzü 


\subsection{Scrum Task Board Kullanan Yazılımlar}

Yazılım sektöründe kullanılan Scrum Task Board özelliğini içeren farklı yazılım araçları bulunmaktadır. Bu yazılım araçlarından en çok kullanılanları JIRA, Trello ve Taiga'dır. Bu yazılım araçları ile ilgili genel bilgilere aşağıda yer verilmiştir.

\subsubsection{Jira}

Proje ve süreç yönetimi işlemleri için firmaların kullanmış olduğu pek çok uygulama vardır. $\mathrm{Bu}$ uygulamaların belki de en önemlilerinden biri Jira'dır. Kullanım kolaylığg, stabil oluşu ve çevik yöntemleri destekliyor olması, Jira'nın yazılım geliştirme dünyasının vazgeçilmez iş takibi uygulamaları arasında yer almasına yol açmıştır. Bunun yanında, Jira pek çok farklı sektörde de kullanılmaktadır. Jira çevik yazılım geliştirme projelerinin planlanması noktasında esnek bir yapıya sahiptir. Scrum'a ilişkin tüm özellikler kolay ve rahat bir şekilde Jira üzerinde uygulanabilir (Agilens, 2006).

\subsubsection{Trello}

Trello, bir yazılım projesi içerisindeki işlerin organize edilip takip edilmesini ve bu işlerin hem web hem de mobil cihazlar üzerinden yönetebilmesine olanak sağlayan bir proje yönetim aracıdır (Writtenhouse, 2016). Bu proje yönetim aracı, proje ile ilgili yapılacak çalışmaların, tamamlanan çalışmaların ve ileriye dönük hedeflerin tek bir ekran üzerinden takip edilmesine ve organize edilmesini sağlamaktadır. Aynı zamanda Trello üzerinden ekip ile birlikte yürütülen yazılım projelerinde ekip elemanlarına belirlenen sürelere göre görevler atanabilmektedir.

\subsubsection{Taiga}

Taiga, yazılım kullanılabilirliği ile ilgili temel problemleri çözmeyi amaçlayan açık kaynaklı bir proje yönetim aracıdır. Trello ve Jira ile aynı mantıkta çalışan Taiga, sadece bu araçlara göre daha basitleştirilmiş araçtır (Taiga Agile, 2019). Kullanımı kolay bir araç olması yazılım geliştiriciler için Taiga'nın ön plana çıkmasını sağlamıştır. Taiga üzerinde bir yazılım projesinin oluşturulması oldukça kolaydır. Taiga üzerinde şablon (çevik veya kanban) seçilir, ardından projenin adı ve açılaması girilir. Proje kolaylıkla oluşturulmuş olunur.

\section{SANAL GERÇEKLIK TEKNOLOJILERI}

Sanal gerçeklik teknolojileri, sanal bir ortamın sanki içindeymiş gibi hissedilmesini sağlayan birtakım kavramlar, araçlar ve teknolojiler bütünüdür. Bu teknolojilerin temelini akıllı telefonlar, tabletler ve yeni nesil sanal gerçeklik gözlükleri oluşturmaktadır. Sanal gerçeklik teknolojileri içerisinde önemli bir yeri olan sanal gerçeklik gözlükleri; sanallığg gösterebilme, sesleri duyurabilme ve nesneleri hareket ettirebilme gibi özellikleri sağlamaktadır. Sanal gerçeklik teknolojileri başlıca Sanal Gerçeklik, Arttırılmış Gerçeklik ve Karma Gerçeklik olarak üç kısma ayrılmaktadır. Sanal gerçeklik teknolojileri ile ilgili bilgiler aşağıda ifade edilmiştir.

\subsection{Sanal Gerçeklik}

Önceleri sadece iki boyutlu (2D) nesneleri tanımlamak için kullanılan Sanal Gerçeklik (Virtual Reality - VR), günümüzde üç boyutlu (3D) nesnelerden oluşan, bilgisayar yazılımları tarafından üretilen ve etkileşimli bir ortamın oluşmasını sağlayan bir teknolojidir (Chittaro ve Ranon, 2007). 
Oluşturulan bu ortam gerçek dünyanın bir simülasyonu ya da tamamen farklı bir yapay ortam olabilir. Bir kullanıcı, bilgisayar yazılımı ile oluşturulan bu ortama VR cihazlarını kullanarak bakabilir, o ortam içerisinde gezinebilir, hareket edebilir ve sanal öğeler ile etkileşime girebilir. Günümüzde VR teknolojisi eğitim-öğretim, bilgisayar oyunları ve savunma sanayi gibi birbirinden çok farklı alanda kullanılmaktadır (Ausburn ve Ausburn, 2004; Lin ve Lan, 2015).

\subsection{Artırılmış Gerçeklik}

Artırılmış Gerçeklik (Augmented Reality - AR), dijital ortamlarda bulunan resim-video gibi sanal nesnelerin gerçek görüntülerin üzerine entegre edilmesini sağlayan bir teknolojidir (Tozkoparan ve Ernur, 2018). Günümüzde mobil cihazlara ek olarak Google ve Microsoft gibi birçok teknoloji firması giyilebilir teknolojiler ve düşük AR cihazları (head-up-display) üzerine çalışmalar yürütmekte ve yeni ürünleri piyasaya çıkartmaktadırlar. Google'ın "Google Glass" (Arockia Panimalar vd., 2017) adlı AR özellikli akıllı gözlügü ile beraber Microsoft'un 2016 yılında piyasaya sürdüğ̈ "HoloLens" (Karthika vd., 2017) adlı akıllı gözlüğü bu alandaki en çok bilinen teknolojik ürünler olarak ön plana çıkmaktadır. Bunun dışında Magic Leap firmasının uzun yıllardır büyük bir gizlilik ile üzerinde çalıştığı ve 2018 yılı sonunda piyasaya sürdüğ̈̈ "HUD (Heads Up Device)", dünya teknoloji piyasasında konuşulan AR tabanlı giyilebilir ürünlere örnek gösterilebilir. AR teknolojileri 2019 yılında çok daha duyacağımız ve karşılaşacağımız bir kavram olacaktır.

\subsection{Karma Gerçeklik}

Karma Gerçeklik (Mix Reality - MR), fiziksel gerçeklik ile sanal gerçekliği aynı yerde harmanlayan ve yeni bir gerçeklik ortaya çıkmasını sağlayan bir teknolojidir. İnsan, çevre ve bilgisayar etkileşiminin bir sonraki evrimi olarak ta adlandırılan bu teknoloji, grafiksel işlem gücündeki artış ve ekran teknolojisindeki gelişmeler sayesinde bugün artık adından söz ettirmektedir. Temel olarak AR ile VR teknolojilerinin bir arada kullanıldığı bir alt yapıya sahiptir (Freeman vd., 2005). Bu teknolojinin kullanımı için pek çok ticari firma tarafından geliştirilmiş farklı özelliklere sahip başlık sistemleri bulunmaktadır. Bu başlık sistemleri içerisinden en çok bilinenleri ve kullanılanları Microsoft HoloLens (Bray vd., 2018), Samsung HMD Odyssey (Carbotte, 2018), Lenovo Explorer (Carbotte, 2018)'dir.

\section{SCRUM TASK BOARD UYGULAMASI}

AR tabanlı Scrum Task Board Uygulaması geliştirilmeden önce yazılımın tüm gereksinimlerinin tespiti için Scrum uygulamasının özelliklerini içeren web tabanlı bir prototip yazılım geliştirilmiştir. Geliştirilen web tabanlı uygulamanın detayları aşağıda yer almaktadır.

\subsection{Web-Tabanlı Scrum Task Board Uygulaması}

Normal şartlarda tahta üzerine asılan kâğıtlardan oluşan Scrum Task Board Uygulaması geliştirilen bir yazılım ile dijital bir ortama alınmıştır. Scrum Task Board Uygulaması web-tabanlı olarak "React.JS and Express" ile geliştirilmiştir. Geliştirilen uygulamanın özellikleri aşağıda verilmiştir:

- Birden fazla proje ekleme.

- Hikâye bilgilerinin metin (text) olarak "Hikâyeler" k1smına eklenebilmesi.

- Her bir hikâyeye ait görevler (task'lar) oluşturulabilmesi.

- Görevlerin durum bilgilerinin kategori temelli olarak değiştirilebilmesi.

- Görevlerin kim tarafından hangi tarihte yapılacağı bilgisinin eklenebilmesi. 
Uygulamanın genel ekran görünümü Şekil-2'de görülmektedir.

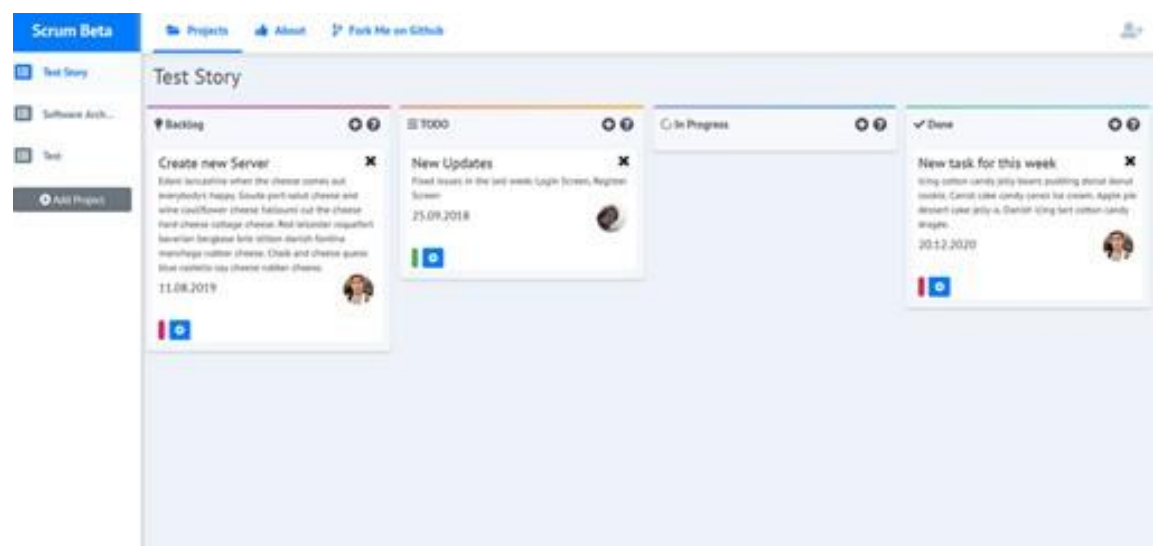

Şekil-2: Web Tabanlı Scrum Task Board Uygulaması

Hikâye Ekleme Modülü: Scrum Task Board Uygulaması içerisine hikâye eklemek için bu modül kullanılmaktadır. Her bir proje ile ilgili eklenen hikâyeler geçmişe dönük olarak ta listelenebilmektedir. Şekil-3'de hikâye ekleme modülü görülmektedir.

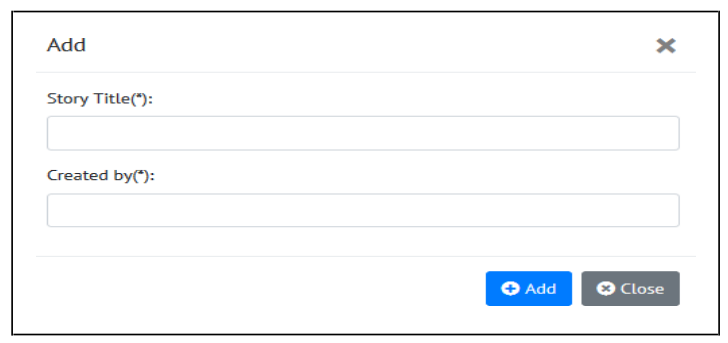

Şekil-3: Hikâye Ekleme Modülü

Kullanıcı Ekleme Modülü: Her bir yazılım projesinde çalışacak proje ekibi "Kullanıcı Ekleme Modülü” üzerinden tanımlanabilmektedir. Şekil-4'de kullanıcı ekleme modülüne ilişkin ekran görülmektedir.

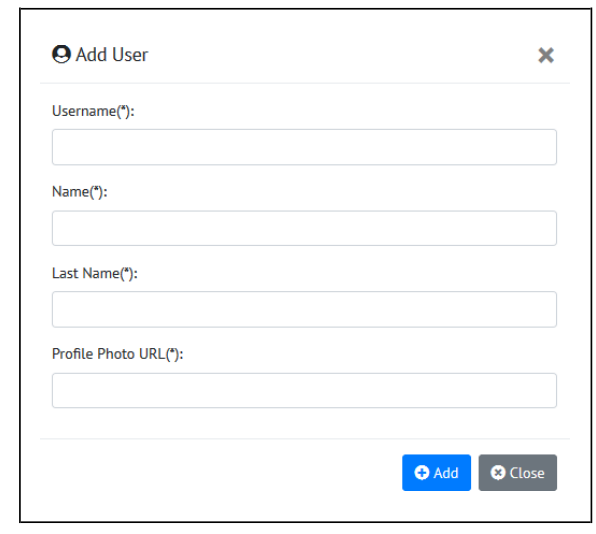

Şekil-4: Kullanıcı Ekleme Modülü 
Görev Ekleme Modülü: Her bir hikâyeye ait görevlerin ayrı ayrı eklenmesi için "Görev Ekleme Modülü” geliştirilmiştir. Görev ekleme modülüne ilişkin ekran görüntüsü Şekil-5'te görülmektedir.

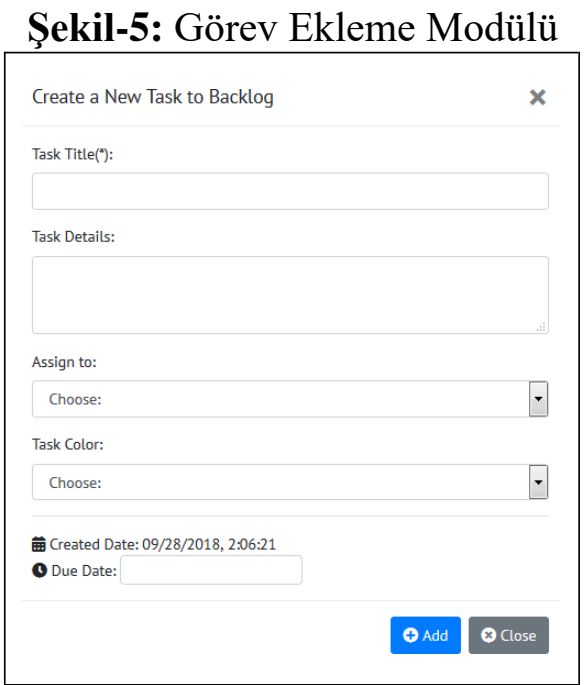

Eklenilen her bir görev bağlı bulunduğu kategoriye göre Scrum Task Board üzerinde görülmektedir. Her bir görevin kategorisi Scrum Task Board üzerinden sürükle bırak özelliği kullanılarak ta güncellenebilmektedir.

\section{AR SCRUM TASK BOARD UYGULAMASI}

\subsection{Geliștirilen Modüller}

AR tabanlı olarak geliştirilen Scrum Task Board uygulaması kendi içerisinde 8 alt modülden oluşmaktadır. Geliştirilen yazılım hem cep telefonu hem de AR başlık sistemleri ile kullanılabilmektedir.

Sistem Kayıt Modülü: Bu modül kullanıcının sisteme kaydının gerçekleştirilmesinde kullanılan modüldür. Kullanıc1; ad, soyad, kullanıcı adı ve parola bilgileri ile sisteme kayıt olur. Eğer sistemde aynı isimde kullanıcı adı yoksa kullanıcının sisteme kaydı başarılı bir şekilde gerçekleştirilir.

Sistem Giriş Modülü: Kullanıcı sisteme giriş işlemini bu modül üzerinden gerçekleştirmektedir. Sisteme giriş yapacak olan kullanıcı, kayıt olduğu kullanıcı adı ve parolasını ilgili alanlara girerek giriş yap butonuna dokunur/bakar. Sistem, kullanıcının kullanıcı adı ve parolasının veri tabanında bulunup bulunmadığını kontrol eder. Bilgiler doğruysa kullanıcı sisteme başarılı bir şekilde giriş yapar.

Sistem Çıkış Modülü: Kullanıcının sistemden çıkış işlemini gerçekleştirmek üzere kullandığ1 modüldür. Kullanıcı ekranın sağ üst tarafında bulunan ' $\mathrm{X}$ ' sembolüne dokunur/bakar. Sistem kullanıcının sistemden çıkış isteğini başarılı bir şekilde gerçekleştirir.

Hikâye Ekleme Modülü: Kullanıcı proje temellerini oluşturan konulardaki hikâyeleri eklemek için bu modülden yararlanır. Kullanıcı sol altta bulunan hikâye ekle butonuna dokunduğunda/baktığında "Hikâye Ekleme" ekranı ile karşılaşır. Kullanıcı bu ekran üzerinde istenilen bilgileri girerek yeni bir hikâye oluşturabilir.

Hikâye Silme Modülü: Kullanıcı proje temellerini oluşturan konulardaki hikâyeleri silmek için bu modülü kullanır. Kullanıcı tablo üzerinde bulunan hikâyelerden silmek istediği hikâyeyi 
seçtiğinde, hikâye silme ekranı açılır. Bu ekranda silmek istediği hikâye ile ilgili bilgileri görür ve sil butonunu kullanarak hikâye silme işlemini gerçekleştirir.

Hikâye Görüntüleme Modülü: Kullanıcı proje temellerini oluşturan konulardaki hikâyeleri görüntülemek için bu modülden yararlanır. Kullanıcı tablo üzerinde bulunan hikâyelerden görüntülemek istediğinin butonuna dokunarak/bakarak açılan ekranda hikâyenin detaylarına ulaşır. $\mathrm{Bu}$ ekranda hikâye bilgilerini görür ve " $\mathrm{X}$ " butonuyla çıkış işlemini gerçekleştirebilir.

Görev Ekleme Modülü: Kullanıcı proje detaylarında önemli rol oynayan görevleri (tasks) eklemek için bu modülden yararlanır. Kullanıcı sağ altta bulunan "Görev Ekle" butonuna dokunduğunda "Görev Ekleme" ekranı ile karşılaşır. Kullanıcı bu ekran üzerinde gerekli alanları doldurarak görev ekleme işlemini gerçekleştirir.

Görev Silme Modülü: Kullanıcı proje içerisinde yer alan bazı görevleri silmek için bu modülü kullanır. Kullanıcı tablo üzerinde bulunan görevlerden silmek istediği görevi seçerek görevin yanındaki ' $\mathrm{X}$ ' ile silme işlemini gerçekleştirir.

Görev Görüntüleme Modülü: Kullanıcı proje detayları içerisinde yer alan önemli görevleri görüntülemek için bu modülden yararlanabilir. Kullanıcı karşısına gelen tabloda ilgili görevin bulunduğu alana erişerek bu görevin detaylarına ulaşır.

\subsection{Kullanılan Teknolojiler ve Yazılım Mimarisi}

Arttırılmış gerçeklik temelli bir Scrum Task Board uygulamasının geliştirilmesi için; Unity, Unity içerisinde bulunan ve AR uygulamaları geliştirmek için kullanılan Vuforia platformu ile MySQL veri tabanı teknolojileri bir arada kullanılmıştır. Scrum Task Board içerisinde bulunan görevler MySQL veri tabanı içerisine kaydedilmiş ve yazılan API (Uygulama Programlama Arabirimi - Application Programming Interface) ile veri tabanındaki bilgilerin Unity'ye aktarılmas1 sağlanmıştır. Unity içerisinden Vuforia aktivasyonu gerçekleştirilmiştir. Geliştirilen AR Scrum Task Board uygulamasınına ait mimari Şekil- 6'da görülmektedir.

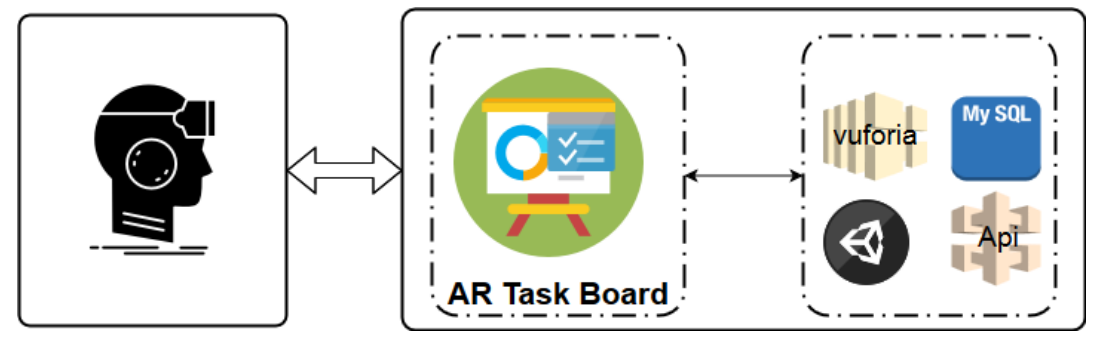

Şekil-6: Geliştirilen AR Scrum Task Board Uygulamasının Mimarisi

Unity sayesinde; kullanıcı arayüzleri, 3D görsel objeler ve her bir arayüz için Unity Scenes adı verilen sahneler oluşturulmuştur. Geliştirilen uygulama Unity teknolojisi ile geliştirildiği için farklı platformlara göre çalışabilecek şekilde düzenlenebilmektedir. Şekil-7'de geliştirilen AR Scrum Task Board uygulamasının bir cep telefonu üzerindeki çalışması görülmektedir. 


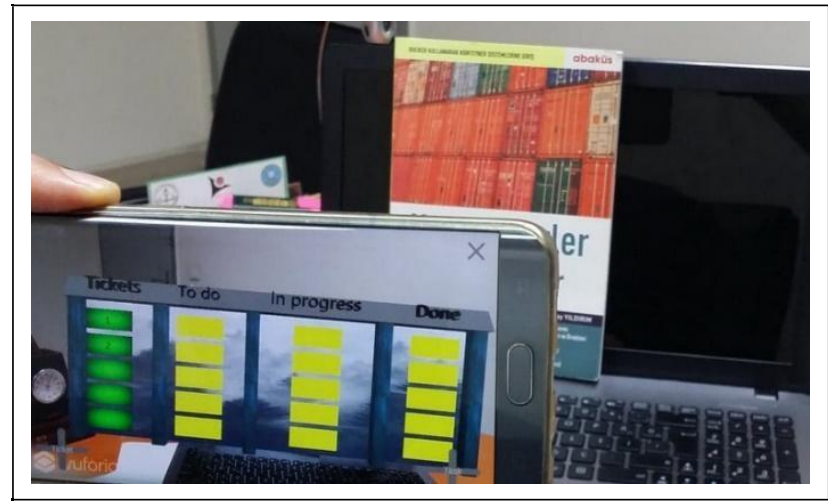

Şekil-7: Geliştirilen AR Scrum Task Board Uygulamasının Ekran Görüntüsü

\section{SONUÇ VE TARTIŞMA}

Yazılım geliştirme teknolojilerinde yaşanan gelişmeler, yazılımların geliştirilmesinde kullanılan yazılım yaşam döngülerinin sürelerinin kısalması, yazılımlardaki kapsamın ve gereksinimlerin artması ile beraber farklı çevik yazılım geliştirme yaklaşımları ortaya çıkmıştır. Çalışmanın ilk aşamasında kâğıt ortamında tutulan Scrum Task Board'ların, oluşturulan web-tabanlı bir yazılıma aktarılması gerçekleştirilmiştir. Geliştirilen web-tabanlı Scrum Task Board uygulaması sayesinde geriye dönük hangi kullanıcının hangi projede hangi işi yaptığı bilgisi tutulmuş ve günlük Scrum toplantıları için kullanılan bir araç olması sağlanmıştır. Çalışmanın ikinci aşamasında ise geliştirilen web-tabanlı Scrum Task Board uygulaması AR tabanlı bir uygulamaya dönüştürülmüştür. AR ile uygulama geliştirmek için kullanılan teknolojilerin henüz yeterli olgunluğa ve kapasiteye sahip olmaması AR tabanlı Scrum Task Board uygulamasının geliştirilmesi aşamasında, prototip olarak geliştirilen web-tabanlı uygulamaya göre daha fazla teknik bilgi ve yeni teknolojinin kullanımını zorunlu kılmıştır. Bu dezavantajına rağmen geliştirilen ve incelendiği kadarıyla literatürde ilk olan AR tabanlı Scrum Task Board uygulaması web-tabanlı uygulamanın gerçekleştirdiği işlemleri yapabilmektedir. Geliştirilen her iki uygulama karşılaştırıldığında, webtabanlı Scrum Task Board uygulamasının AR tabanlı Scrum Task Board uygulamasına göre kullanımının daha kolay olduğu, daha az teknoloji ve teknik bilgi gerektirdiği görülmüştür. Önümüzdeki süreçte teknik imkânların ve kabiliyetlerin artması ile birlikte yukarıda sözü edilen AR tabanlı uygulama geliştirme dezavantajlarının kalkacağı düşünülmektedir.

\section{KAYNAKÇA}

Agile Business Consortium (2019). What is DSDM?. https://www.agilebusiness.org/what-is-dsdm. (Erişim Tarihi: 13.04.2019).

Agilens (2019). Atlassian JIRA Agile. https://agilens.wordpress.com/blog/agile- tools/atlassian-jiraagile/. (Erişim Tarihi: 26.04.2019).

Arockia Panimalar S., Tamilselvi K., Vani K., Pattabi M., Roodiet V., Nandhini S., Muthumeenal L. (2017). Google Glass Technology. International Research Journal of Engineering and Technology, 4(8), 1121-1124.

Arslan S., Yücalar F. (2016). Bir elektronik tasarım firmasında hata takip ve proje yönetim sistemi uygulamas1. Pamukkale University Journal of Engineering Sciences, 22(2), 85-93.

Asproni G. (2006). An Introduction to Scrum. Software Developer's Journal, 1-10. 
Atlassian (2019). Jira Software. https://www.atlassian.com/software/jira. (Erişim Tarihi: 15.04.2019).

Ausburn L. J., Ausburn F. B. (2004). Desktop Virtual Reality: A Powerful New Technology for Teaching and Research in Industrial Teacher Education, Journal of Industrial Teacher Education, 41(4), 1-16.

Basecamp (2019). https://basecamp.com/. (Erişim Tarihi: 16.04.2019).

Beck K., Andres C. (2004). Extreme Programming Explained: Embrace Change, 2nd Edition, Addison- Wesley.

Blossom (2019). Project tracking for distributed companies. https://www.blossom.co/. (Erişim Tarihi: 16.04.2019).

Bray B., Mcculloch J., Schonning N., Zeller M. (2018). What is mixed reality?. https://docs.microsoft.com/en-us/windows/mixed-reality/mixed-reality. (Erişim Tarihi: 04.05.2019).

Carbotte K. (2018). Lenovo Explorer Windows Mixed Reality Headset Review: A Low-Cost VR OnRamp. https://www.tomshardware.com/reviews/lenovo-explorer-windows-mixed-realityvr,5468.html. (Erişim Tarihi: 04.05.2019).

Carbotte K. (2018). Samsung HMD Odyssey Windows Mixed Reality Headset Review. https://www.tomshardware.co.uk/samsung-odyssey-windows-mixed-reality-hmd-vr,review34278-2.html. (Erişim Tarihi: 04.05.2019).

Chittaro L., Ranon R. (2007). Web 3D technologies in learning, education and training: Motivations, issues, opportunities. Computers \& Education, 49(1), 3-18.

Codebase (2019). https://startupstash.com/project-management/codebase/. (Erişim Tarihi: 16.04.2019).

Çamoğlu K., Akbayir D., Yücalar F., Bayrakli S. (2010). Bir Çevik Yazılım Geliștirme Sürecinin Uyarlanması ve Uygulanması. Havacılık ve Uzay Teknolojileri Dergisi, 4(3), 57-67.

Deemer P., Benefield G., Larman C., VODDE B. (2012). The Scrum Primer: A Lightweight Guide to the Theory and Practice of Scrum. http://scrumprimer.org/scrumprimer20.pdf. (Erişim Tarihi: 26.04.2019).

Dijital Maden (2019). Asana Nedir? Nasıl Kullanılır?. https://dijitalmaden.com/asana-nedir-nasilkullanilir. (Erişim Tarihi: 15.04.2019).

Freeman R., Steed A., Zhou B. (2005). Rapid scene modelling, registration and specification for mixed reality systems. Proceedings of the ACM symposium on Virtual reality software and technology. Monterey, CA, USA, 147-150.

Karthika S., Praveena P., Gokilamani M. (2017). HoloLens. International Journal of Computer Science and Mobile Computing, 6(2), 41-50.

Kruchten P. (2003). The Rational Unified Process: An Introduction. 3rd edition, Addison-Wesley Professional.

Lacey M. (2012). The Scrum Field Guide: Practical Advice for Your First Year. 1st Edition. Agile Software Development Series. Addison-Wesley Professional.

Lin T. J., Lan, Y. J. (2015). Language Learning in Virtual Reality Environments: Past, Present, and Future. Educational Technology \& Society, 18(4), 486-497.

Palmer S. R., Felsing J. M. (2002). A Practical Guide to Feature-Driven Development. 1st Edition. Prentice Hall. 
Paranj B. (2017). Test-Driven Development in Ruby: A Practical Introduction to TDD Using Problem and Solution Domain Analysis. 1st Edition, Apress.

Pivotal TrackER (2019). Pivotal Tracker: Agile Project Management. https://www.pivotaltracker.com/. (Erişim Tarihi: 16.04.2019).

Poppendieck M., Poppendieck, T. (2003). Lean Software Development: An Agile Toolkit. AddisonWesley Professional.

Rubin K. S. (2012). Essential Scrum: A Practical Guide to the Most Popular Agile Process. 1st Edition. Addison- Wesley Professional.

Schach S. R. (2011). Object-Oriented and Classical Software Engineering, 8th Edition, McGrawHill.

Schwaber K. (2004). Agile Project Management with Scrum. Microsoft Press.

Sendtask (2019). https://sendtask.io/. (Erişim Tarihi: 16.04.2019).

Sprinthly (2019). Agile issue tracking - sprint.ly. https://sprint.ly/. (Erişim Tarihi: 16.04.2019).

Sutherland J. (2014). Scrum: The Art of Doing Twice the Work in Half the Time. 1st Edition. Currency.

Taiga Agile (2019). Why We Did It?. https://taiga.io/. (Erişim Tarihi: 15.04.2019).

Tozkoparan G., Ernur O. (2018). Dijital Dönüşüm Perspektifinde Endüstri 4.0 Sürecindeki İşletmelerin Karşılaştığı Durumlar Üzerine Bir Vaka Çalışması. Uluslararası Sosyal Bilimler ve Inovasyon Kongresi, 385-397. Antalya, Turkey.

Turner M. (2006). Microsoft Solutions Framework Essentials. 1st Edition. Microsoft Press.

Vivify Scrum (2019). Agile Project Management Software. https://www.vivifyscrum.com/. (Erişim Tarihi: 16.04.2019).

Writtenhouse S. (2016). A Guide to Trello for Life and Project Management. MakeUseOf. https://www.makeuseof.com/tag/guide-trello-life-project-management/. (Erişim Tarihi: 15.04.2019).

Yücalar F., Borandağ E. (2019). Yazılım Mühendisliğinde Modern Yaklaşımlar. 1. Bask1, Nobel Akademik Yayıncılık, Ankara. ISBN: 978-605-7928-99-3. 